\title{
Knitting Force Measurement on Flat Knitting Machines
}

\author{
A. Fouda, A. El-Hadidy, and A. El-Deeb \\ Textile Engineering Department, Faculty of Engineering, Mansoura University, Mansoura 35516, Egypt \\ Correspondence should be addressed to A. Fouda; abdo_faheem@mans.edu.eg
}

Received 8 May 2014; Revised 8 July 2014; Accepted 11 July 2014; Published 5 August 2014

Academic Editor: Nabil Ibrahim

Copyright (@) 2014 A. Fouda et al. This is an open access article distributed under the Creative Commons Attribution License, which permits unrestricted use, distribution, and reproduction in any medium, provided the original work is properly cited.

\begin{abstract}
Knittability can be defined as the ability of yarns to run on knitting machines without problems. Knittability can be achieved when less stress is applied on the knitting machine parts by the knitting yarns. This paper presents a novel measuring system for the knitting force needed to perform knitting yarns on flat knitting machine based on data acquisition system (DAS). The proposed system is used to measure the knitting force at different machine settings and different properties of the knitting yarns to determine the optimal production conditions. For this reason, three types of knitted fabric structures (single jersey, Rib $1 \times 1$, and full cardigan) with three different loop lengths and five different twists of ply yarn were produced. The obtained results showed the optimal yarn ply twist factor $\left(\alpha_{e}\right)$ which gave minimum knitting force (less stress on needles or knitting yarns) at different loop lengths for each structure.
\end{abstract}

\section{Introduction}

In textile industry, there is mutually stress between materials and machine parts, such as traveler and spinning yarn on spinning machines, heald eyes and warp threads on weaving machines, and sewing needle and sewing thread, sewing needle and fabrics on sewing machines. In the knitting industry there is a stress between the needle hook and knitting yarn during withdrawal of the new loop and between stem, latch of the needle, and old loop during knock-over process.

Consequently, the study of these stresses helps to design and manufacture each knitting needle and knitting machines parts. Also, it helps to determine knitting yarns specifications in order to preserve the parts of knitting machinery from damage for a longer period and keep the knitting yarns from breakages to avoid all of the defects and low production.

The previous searches aimed to study knitting force theoretically and practically at different knitting variables such as the knitting machine settings (machine speed, type of needles, cam setting, input, and take-down tension), knitted fabric structures, and knitted yarn properties.

Wray and Burns $[1,2]$ developed a transducer system to measure the dynamic forces between a latch needle and the stitch and guard cams during the formation of a knitted loop.
Dönmez and Marmarali [3] recorded the number of machine stops, yarn breaks, and holes, for Rib $1 \times 1$ produced with thirty different yarns. They proved that two equations depending on yarn characteristics can be used to predict yarn-needle and yarn-yarn friction.

$\mathrm{Hu}$ and Zhu [4] proposed a quantitative method used for assessing the degree of glass filament breakage during the weft knitting, and also they studied and analyzed the effects of different factors such as cam setting, knitted structures, and yarn parameters.

Liu et al. [5] studied the effect of yarn parameters on the knittability of glass ply yarn. They found that a finer fiber diameter, higher twist, and optimized ply structure can make the yarn stronger and more durable during the knitting process.

Kowalski et al. [6] illustrated the characteristics of dynamic thread loads in the knitting zone of weft knitting machines based on a probabilistic model. They found that the forces increase if the knocking-off depth of needles in the knitting zone is increased.

However, all these studies can be considered as an indirect method to demonstrate the knittability because they measured indirect parameters such as number of holes in fabrics and number of thread breakage. Also, most of these studies did not present the optimal settings during the production 


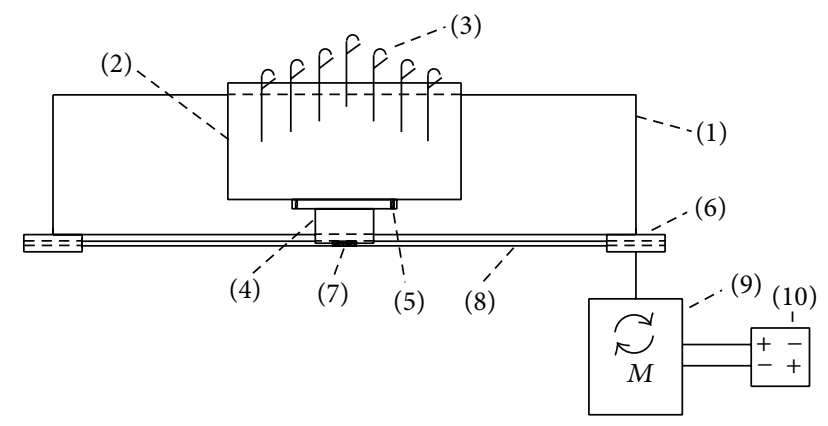
(1) Needle bed
(6) Pulley
(2) Machine carriage
(7) Link
(3) Latch needles
(8) Belt
(4) Connecting piece
(9) DC motor
(5) Fixed screw
(10) Electric current

FIGURE 1: Diagrammatic sketch for flat knitting machine.

of knitted fabric structures which means the production with less stresses on needles or knitting yarns.

Therefore, the first aim of this research is to attempt to measure these stresses dynamically on knitting machine during production under actual operating condition with multiple settings of the machine and disparate yarns specifications. The second aim is to determine the optimal production setting for different knitted fabric structures.

\section{Test Methods}

To achieve the first aim, a measuring system is implemented practically to collect the data with the help of DAS. The principle of this measuring system is based on the change in a measured voltage as an indication to the change in knitting force. The change in voltage is resulting from a change in electrical resistance of a sensing element (strain gauge) which is affected by the knitting force. For the purpose of data analysis and to achieve the second aim, a subroutine program was written in Matlab environment.

2.1. Sensing Element. The diagrammatic sketch of the flat knitting machine is shown in Figure 1.

The sensing element is fixed on the connecting piece (4) which transfers the reciprocated movement from the DC motor (9) to the machine carriage (2). The reciprocated movement is transferred from the DC motor to the connecting piece by the belt (8) and the pulley (6). The connected piece is a metallic part of stainless steel on the form of double angle leaver $2 \mathrm{~mm}$ thickness as shown in Figure 2(a). Two strain gauges each of $120 \Omega$ foil resistance are fixed on the connecting piece as shown in Figure 2(b). The best position of the strain gauge resistances is determined by ANSYS Program.

Due to the up and down of the needles fed with different knitting yarns, stresses are applied on the connecting piece and in consequence cause a tension/compression displacement in the strain gauges, as we see Figure 3.

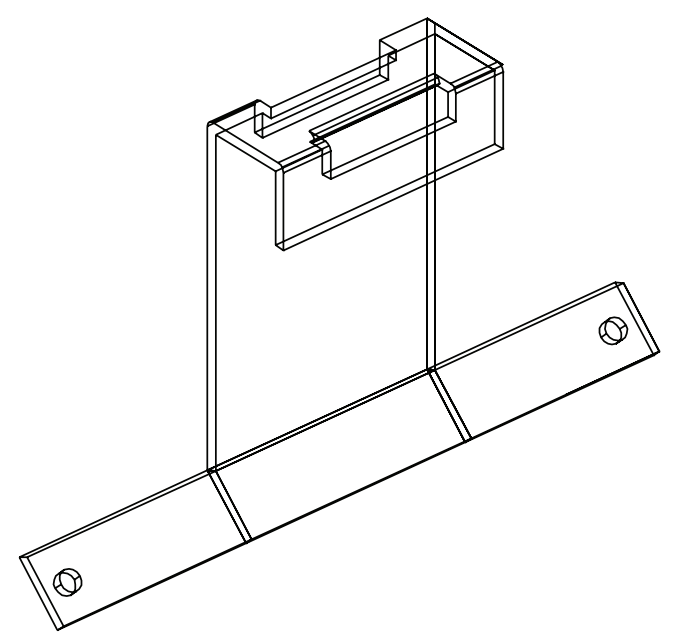

(a)

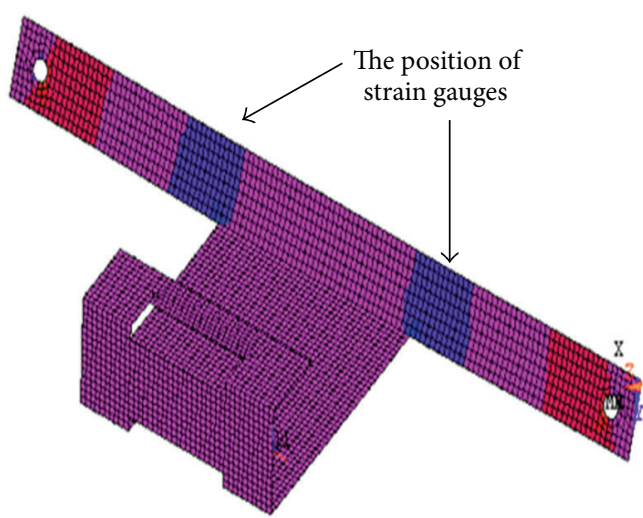

(b)

FIGURE 2: The connecting piece: (a) isometric shape and (b) ANSYS picture.

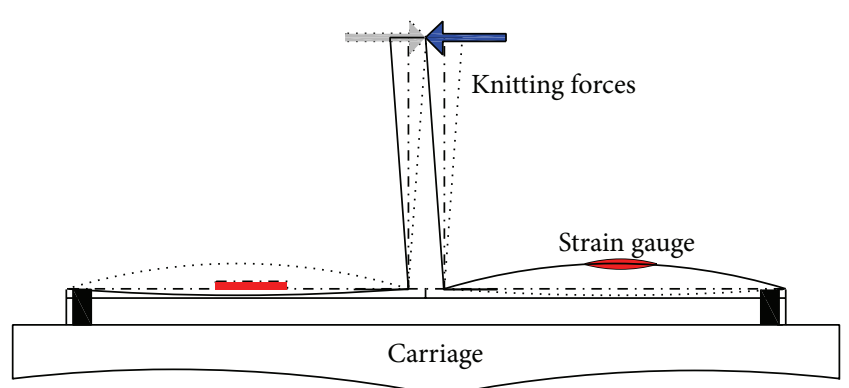

FIGURE 3: The stresses on the sensing element due to knitting force.

According to the change of the strain gauge dimension, the output voltage is changed as a representation of the knitting force.

It can be noted that the change of the output voltage of the strain gauge is small due to its structure technique, so a voltage amplification circuit is needed to allow recording of the output voltage. 


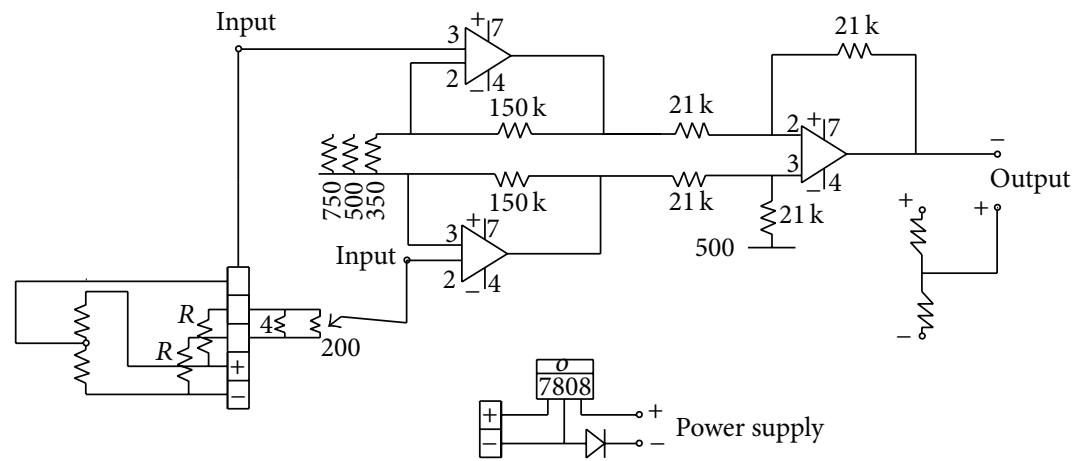

FIgURE 4: Measuring circuit.

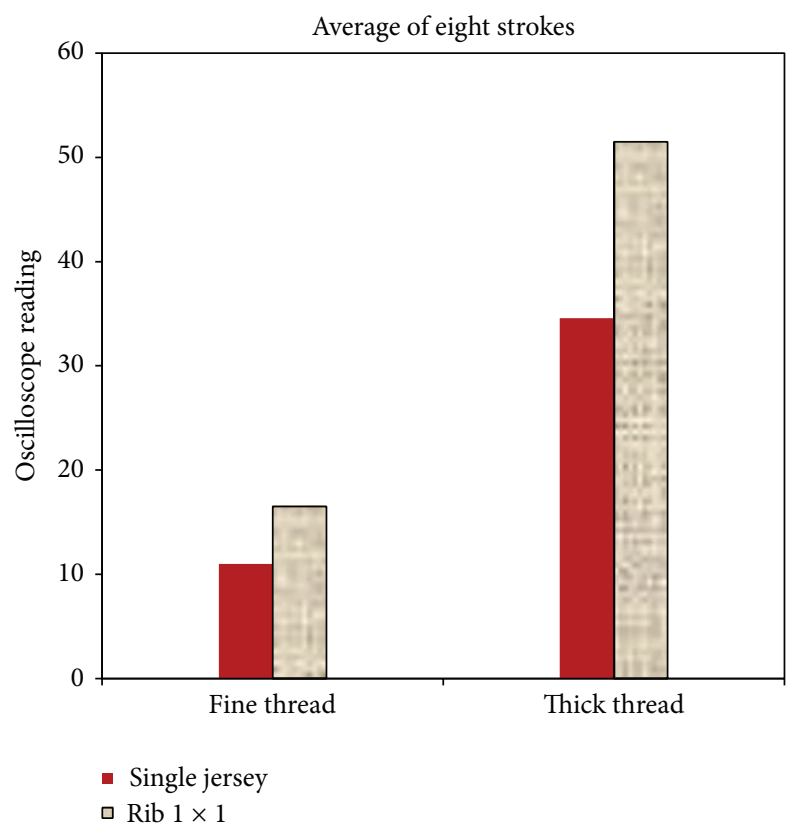

FIgURE 5: Sensitivity of the measuring system.

The overall measuring circuit is shown in Figure 4 and the output voltage of this circuit is recorded by PCSU1000 digital storage oscilloscope.

2.2. Sensitivity and Calibration of the Measuring System. To insure the sensitivity of the measuring system at different parameters, the signals are recorded for two knitted fabric structures and two different yarn counts. The tested fabric structures are single jersey and Rib $1 \times 1$.

Figure 5 displays the absolute oscilloscope readings for the average of eight knitting strokes. It is clear that the oscilloscope reading for Rib $1 \times 1$ structure is higher than the single jersey structure. Also, for each structure the thick yarns give higher reading than the fine yarns. So, it can be insured that the measuring system is sensitive for any change in knitting parameters.

In order to convert the absolute display values of the digital oscilloscope to force unite $(\mathrm{cN})$, a static calibration is executed. A connecting piece is fixed on a straight bar and weights are suspended on the end of a cantilever beam.

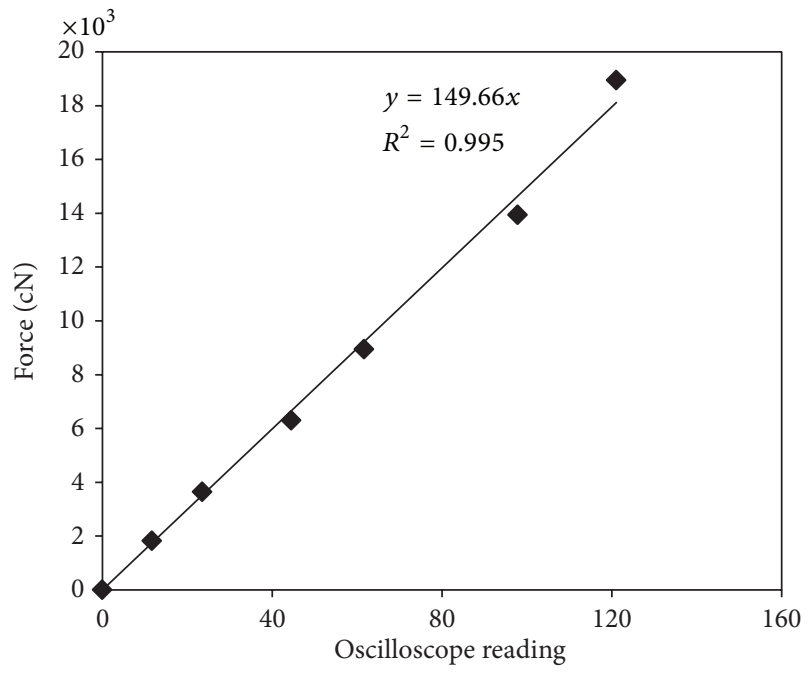

FIGURE 6: Calibration of the measuring system.

The weights are increased gradually and then decreased gradually, and the signals are recorded for each weight step.

Figure 6 shows the curve represents the relation between the absolute display values of the digital oscilloscope and the knitting force $(\mathrm{cN})$. With the help of curve fitting, the calibration equation is determined and given by

$$
Y=149.66 X \text {. }
$$

2.3. Signal Analysis. In this section, the analysis of the measured signals is illustrated.

Figure 7 shows the recorded signal during the movement of knitting machine carriage from right to left and vice versa. It is clear that there is symmetry between both halves of the recorded signal around the zero line. Therefore, the analysis of the signal is applied for one upper half of the signal which represents the movement of the carriage from right to left as shown in Figure 8.

Figure 8 shows the recorded signal for four strokes for the movement of the carriage from right to left. It should be noted that each stroke has two peaks A and B. Peak A represents the stresses in the knitting zone while peak $B$ represents the stresses applied on the sensing element during the reverse of the carriage direction. 


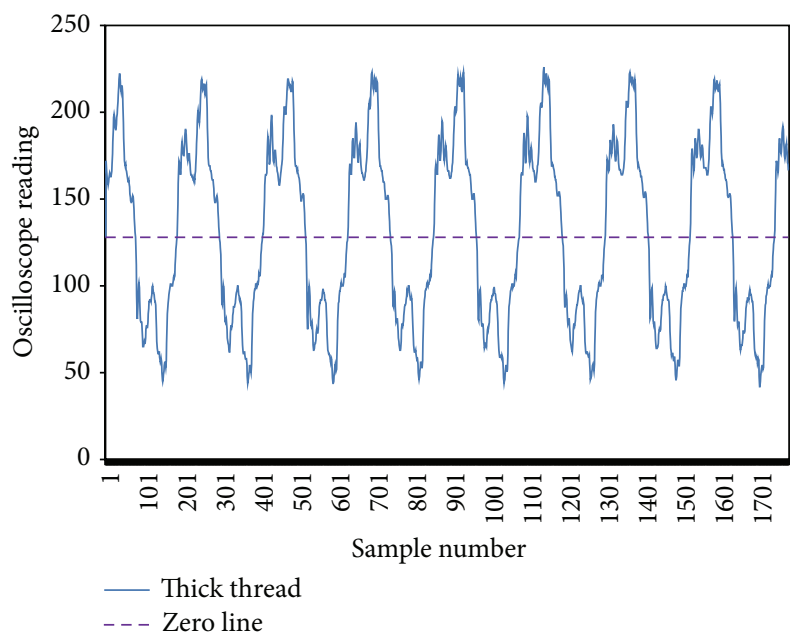

Figure 7: Recorded signal in two directions.

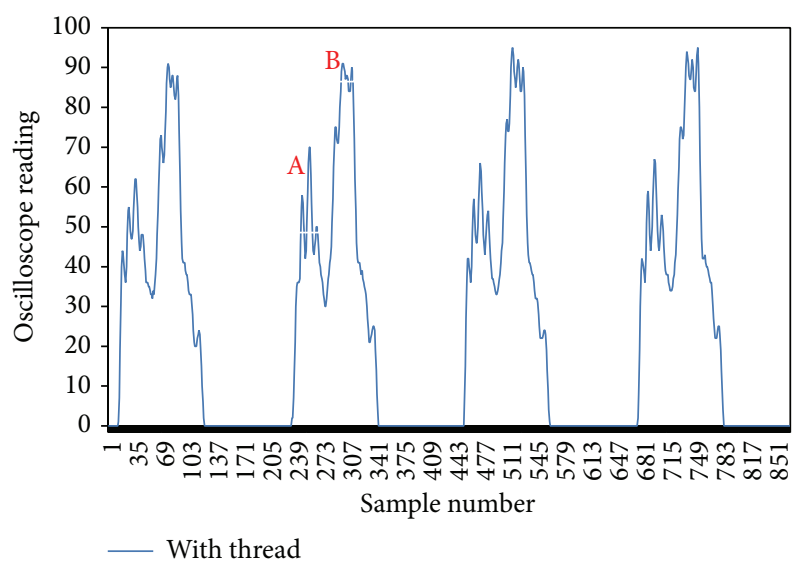

FIGURE 8: Recorded signal during carriage movement from right to left.

For the purpose of study the stresses are during the knitting zone, and two position sensors (project light receiver) are used to determine the knitting zone. The arrangement of the position sensor is shown in Figure 9.

Figure 10 shows the recorded signal from the measuring system for one stroke and the position sensor output during the same stroke.

During the knitting zone the knitting force results from the yarns $\left(S_{T}\right)$ that are estimated by the following steps.

Step 1. The machine is operated without yarns, and the signals are recorded for fifty strokes. The highest value of each stroke $(N)$ is used to estimate the average value $\left(N_{a}\right)$ that is shown in

$$
N_{a}=\frac{\sum_{i=1}^{50} N_{i}}{50} .
$$

Step 2. The machine is operated with yarns, and the signals are recorded for fifty strokes also. With the help of the calibration

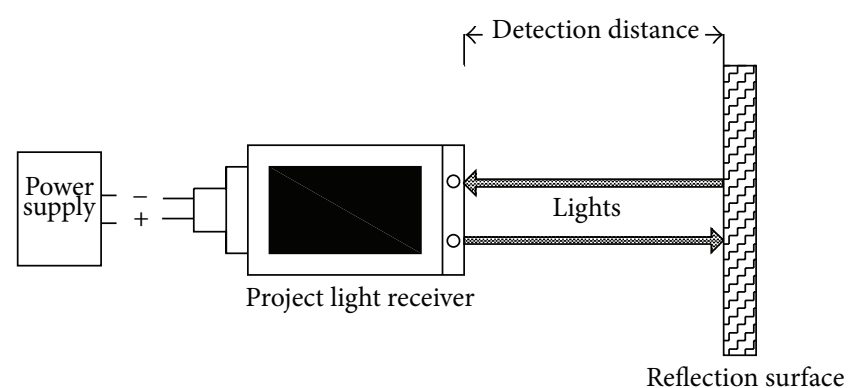

FIgURE 9: Arrangement of the position sensor.

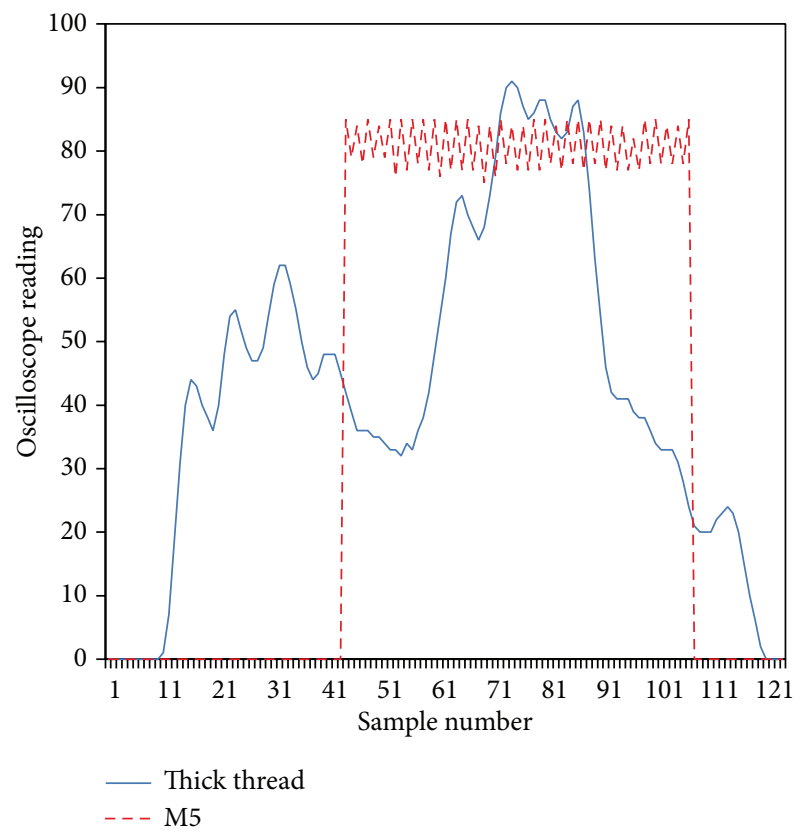

FIGURE 10: Determination of the knitting zone.

equation (1), the values of the recorded signals for the operation with and without yarns cases are converted from oscilloscope readings to knitting force $(\mathrm{cN})$. The knitting force results from the yarns $\left(S_{T}\right)$ that are calculated by subtracting the average value $\left(N_{a}\right)$ from the highest value of the signal during operation with yarns $(T)$ for the fifty strokes as shown in

$$
S_{T i}=T_{i}-N_{a}
$$

Step 3. The maximum (Max), minimum (Min), average, and the coefficient of variation (C.V) values of $\left(S_{T i}\right)$ are calculated.

The average value of $\left(S_{T i}\right)$ is given in

$$
\text { average }=\frac{\sum_{i=1}^{50} S_{T i}}{50}
$$

where $i$ is the number of stroke from 1 to 50 .

In order to analyze the recorded signals directly, a subroutine program is written in Matlab environment as shown by steps in Figure 11. 


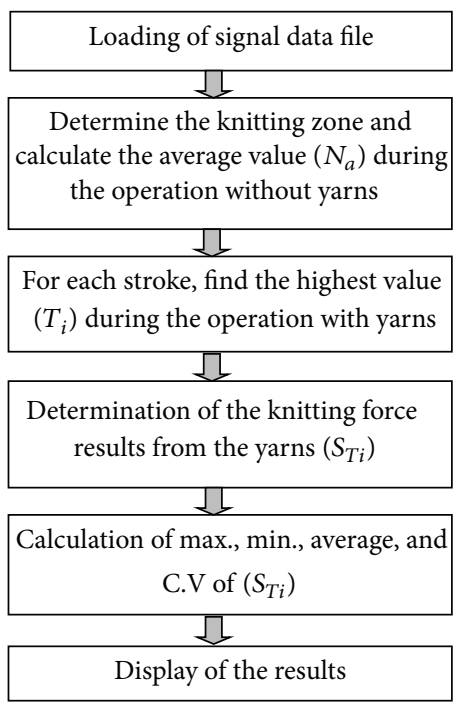

FIGURE 11: Flowchart of the subroutine program steps.

Figure 12 shows the output of the program for a test. As shown in this figure, graph (a) represents the oscilloscope recorded signal of the knitting machine carriage movement in two directions. Graph (b) represents two signals of one stroke for knitting machine carriage with and without yarns. Graph (c) shows the signal of the dynamic knitting forces during the operation with yarns and the average value of the knitting force $\left(N_{a}\right)$ during the operation without yarns. The knitting forces of the fifty successive strokes $\left(S_{T i}\right)$ are shown in graph (d). Finally, table (e) shows the maximum, minimum, average, and the coefficient of variation of the knitting forces.

\section{Experimental Work}

In this section, the proposed measuring system is used to measure the knitting force for the main knitted fabric structures on PASSAP 600 flat knitting machine.

Table 1 demonstrates the experiment plan for the purpose of testing. Three factors are taken into account during the experimental work. Firstly, three knitted fabric structures (single jersey, Rib $1 \times 1$, and Full cardigan) were used. Secondly, three different loop lengths are used by changing the stitch cam setting. Finally, five different twists of ply yarn are implemented by varying the twist inserted per meter $\{0,100$, $150,200$, and $250(\mathrm{~T} / \mathrm{m})\}$. The material used is acrylic and the used yarn count is $8.4 / 5 \mathrm{Ne}$.

Figure 13 shows the relationship between the stitch cam setting and loop length for the three knitted fabric structures. It is clear that the loop length is increased linearly with the stitch cam setting for all structures. It should be noted that each structure has a specific range of the stitch cam setting and consequently a range of the loop length ssee Figure 13 and Table 1$\}$.

\section{Results and Discussions}

The effect of the yarn ply twist factor on the knitting force is studied in this section. The test results for three weft knitted
TABLE 1: Experimental plan.

(a)

\begin{tabular}{ccccc}
\hline \multirow{2}{*}{ Structure } & Yarn ply twist $(\mathrm{T} / \mathrm{m})$ & \multicolumn{4}{c}{ Stitch Cam Setting } \\
& 7 & 7.5 & 8 \\
\hline \multirow{3}{*}{ No yarn } & $\sqrt{ }$ & $\sqrt{ }$ & $\sqrt{ }$ \\
& 0 & $\sqrt{ }$ & $\sqrt{ }$ & $\sqrt{ }$ \\
& 100 & $\sqrt{ }$ & $\sqrt{ }$ & $\sqrt{ }$ \\
& 150 & $\sqrt{ }$ & $\sqrt{ }$ & $\sqrt{ }$ \\
& 200 & $\sqrt{ }$ & $\sqrt{ }$ & $\sqrt{ }$ \\
& 250 & $\sqrt{ }$ & $\sqrt{ }$ & $\sqrt{ }$ \\
\hline
\end{tabular}

(b)

\begin{tabular}{ccccc}
\hline \multirow{2}{*}{ Structure } & Yarn ply twist $(\mathrm{T} / \mathrm{m})$ & \multicolumn{4}{c}{ Stitch Cam Setting } \\
& No yarn & $\sqrt{ }$ & 6 & 7 \\
\hline \multirow{3}{*}{ Rib $1 \times 1$} & 0 & $\sqrt{ }$ & $\sqrt{ }$ & $\sqrt{ }$ \\
& 100 & $\sqrt{ }$ & $\sqrt{ }$ & $\sqrt{ }$ \\
& 150 & $\sqrt{ }$ & $\sqrt{ }$ & $\sqrt{ }$ \\
& 200 & $\sqrt{ }$ & $\sqrt{ }$ & $\sqrt{ }$ \\
& 250 & $\sqrt{ }$ & $\sqrt{ }$ & $\sqrt{ }$ \\
\hline
\end{tabular}

(c)

\begin{tabular}{ccccc}
\hline \multirow{2}{*}{ Structure } & Yarn ply twist (T/m) & \multicolumn{4}{c}{ Stitch Cam Setting } \\
& No yarn & 3.5 & 4.5 & 5 \\
\hline \multirow{3}{*}{ Full cardigan } & 0 & $\sqrt{ }$ & $\sqrt{ }$ & $\sqrt{ }$ \\
& 100 & $\sqrt{ }$ & $\sqrt{ }$ & $\sqrt{ }$ \\
& 150 & $\sqrt{ }$ & $\sqrt{ }$ & $\sqrt{ }$ \\
& 200 & $\sqrt{ }$ & $\sqrt{ }$ & $\sqrt{ }$ \\
& 250 & $\sqrt{ }$ & $\sqrt{ }$ & $\sqrt{ }$ \\
& & $\sqrt{ }$ & $\sqrt{ }$ & $\sqrt{ }$ \\
\hline
\end{tabular}

fabric structures at three different loop lengths are presented and discussed.

4.1. Single Jersey Fabrics. One sample of a single jersey fabric structure is produced and the signal is recorded by the proposed measuring circuit and processed by the written program as discussed in the previous sections. Figure 14 illustrates a printout of the written program output for tested single jersey fabric structure at yarn ply twist factor $4\left(\alpha_{e}\right)$ and loop length $16 \mathrm{~mm}$.

The test is repeated for the same fabric structure and different yarn ply twist factor and loop length as discussed in Section 3. To study the knitting force and to determine the optimum setting, the average knitting force is recorded during each test. This test plan is implemented for all produced fabric structures in this research.

Figure 15 shows the effect of yarn ply twist factor on the knitting force in single jersey knitted fabrics at different levels of loop length.

It should be noted that the knitting force decreases significantly as the yarn ply twist factor increases for the range from 0 to $1.98\left(\alpha_{e}\right)$ of the ply twist factor for the three levels 


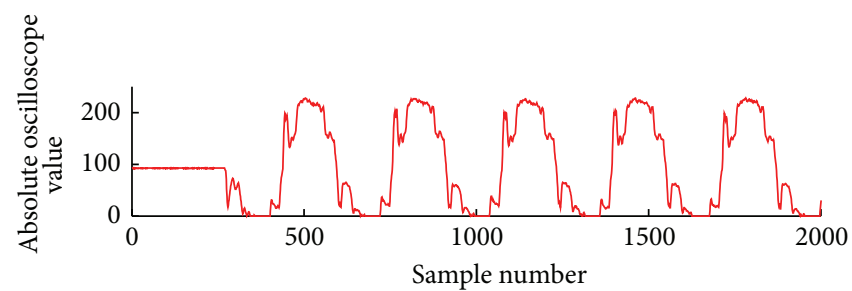

(a)

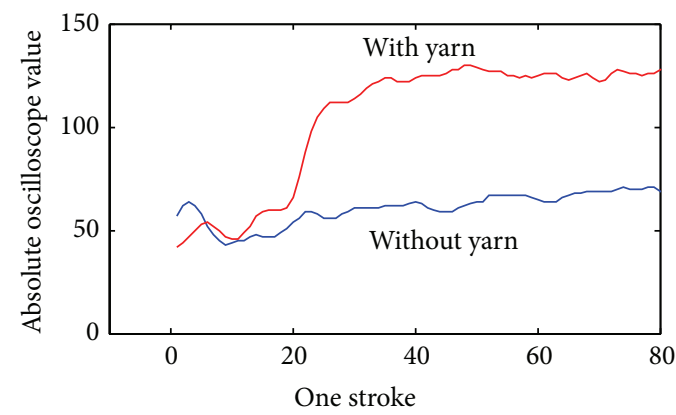

(b)

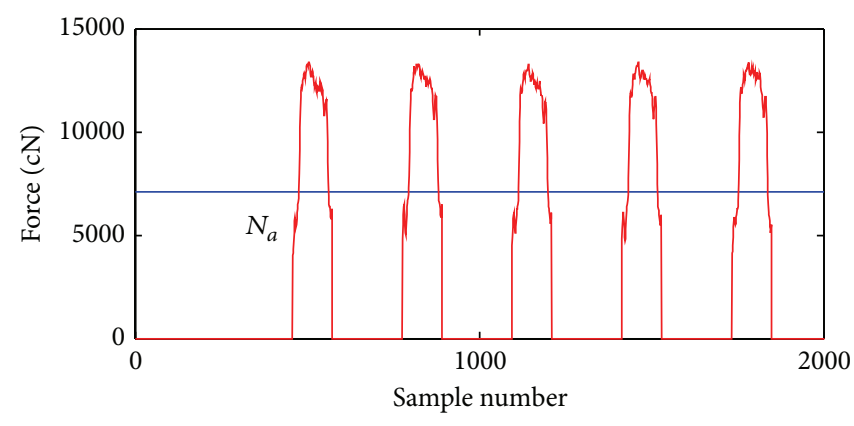

(c)

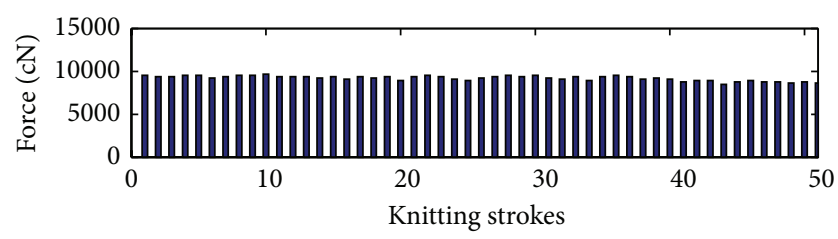

(d)

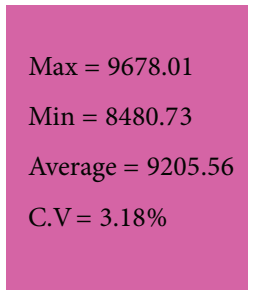

(e)

FIGURE 12: The output of the subroutine Matlab program.

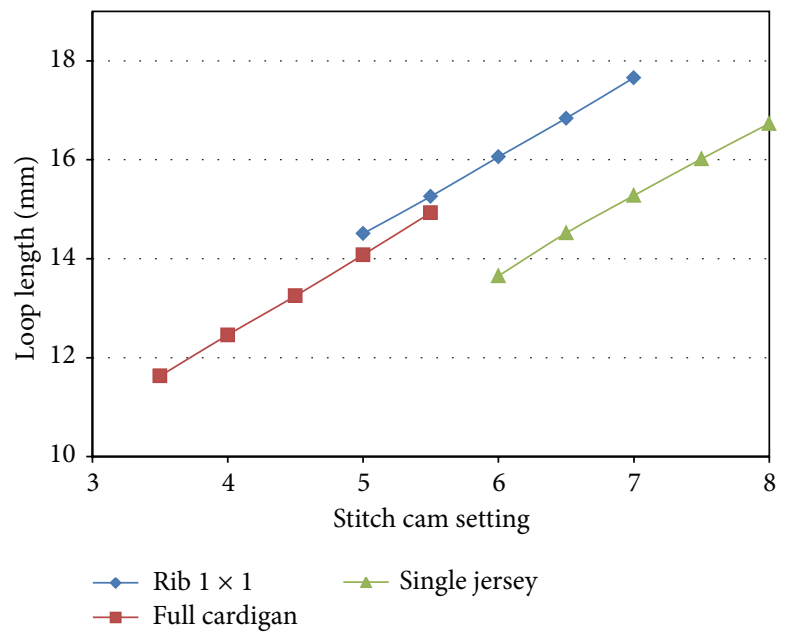

FIGURE 13: Effect of cam setting on loop length. 


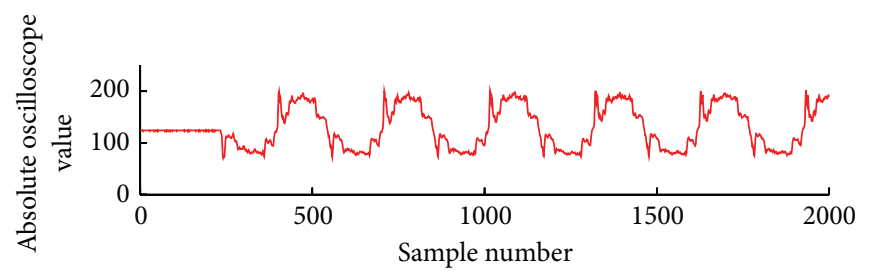

(a)

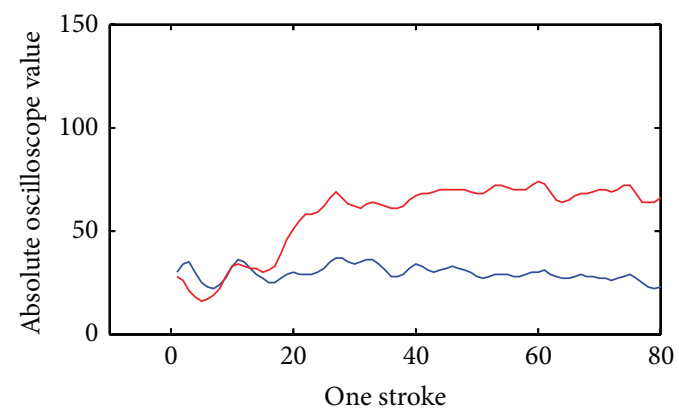

(b)

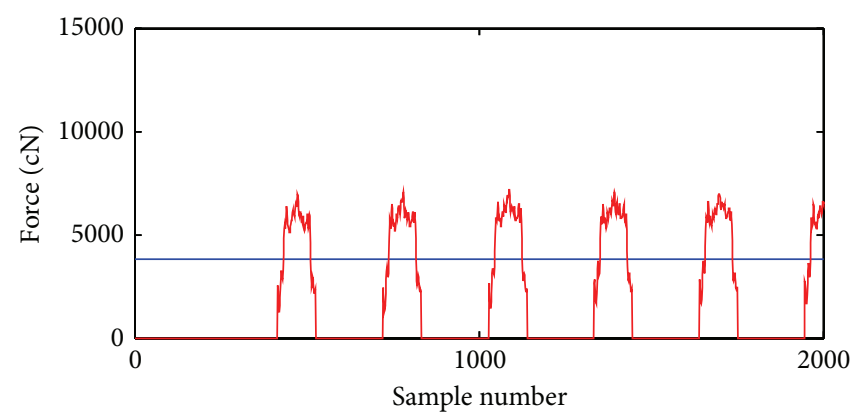

(c)

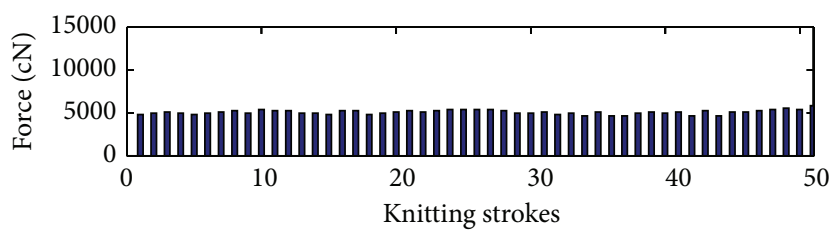

(d)

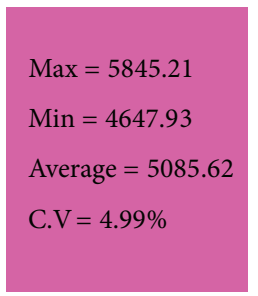

(e)

FIGURE 14: Output program for one single jersey samples.

of loop length. It is may be justified as the increase of the yarn ply twist factor for a specific level decreases the friction area between the yarn and the needle hook and consequently decreases the knitting force.

It also can be found that if the yarn play twist factor is increased than $1.98\left(\alpha_{e}\right)$, the knitting force ascends in a fluctuated trend. It is because increasing of the yarn ply twist factor for higher levels increases the pending rigidity of the yarn.

It is evident from Figure 15 that the behavior of the knitting forces is nearly the same for the three levels of the loop length. However, as the loop length is increased, the knitting force increased, due to increased moved distance of old loop on needle stem.

It should be noted that the yarn ply twist factor of $1.98\left(\alpha_{e}\right)$ has less knitting force for all levels of loop lengths especially at $15.3 \mathrm{~mm}$. It is obvious that at the loop length of $15.3 \mathrm{~mm}$ the knitting force is decreased by $36 \%$ compared with its value for the loop length of $16.7 \mathrm{~mm}$ and it is decreased by $32 \%$ approximately compared with its value at zero yarn ply twist factor. This point can be considered as the optimum setting for single jersey fabric structure which gives minimum knitting force.

4.2. Rib $1 \times 1$ Fabrics. It is well known that Rib $1 \times 1$ knitted fabrics has a different method of the yarn track during the formation compared to single jersey knitted fabrics. In Rib $1 \times 1$ knitted fabrics the yarns pass from the front needles to the back needles and vice versa, and therefore, the knitting force increases.

Figure 16 illustrates the effect of yarn ply twist factor on the knitting force in Rib $1 \times 1$ knitted fabrics at different levels of loop length.

It can be seen that the knitting force decreases dramatically as the yarn ply twist factor increases for the range from 0 to $1.98\left(\alpha_{e}\right)$ of the ply twist factor and it increases significantly for yarn ply twist factor over $1.98\left(\alpha_{e}\right)$ regardless of the loop length. Also, it can be observed that the loop length has no significant effect on the knitting force. 


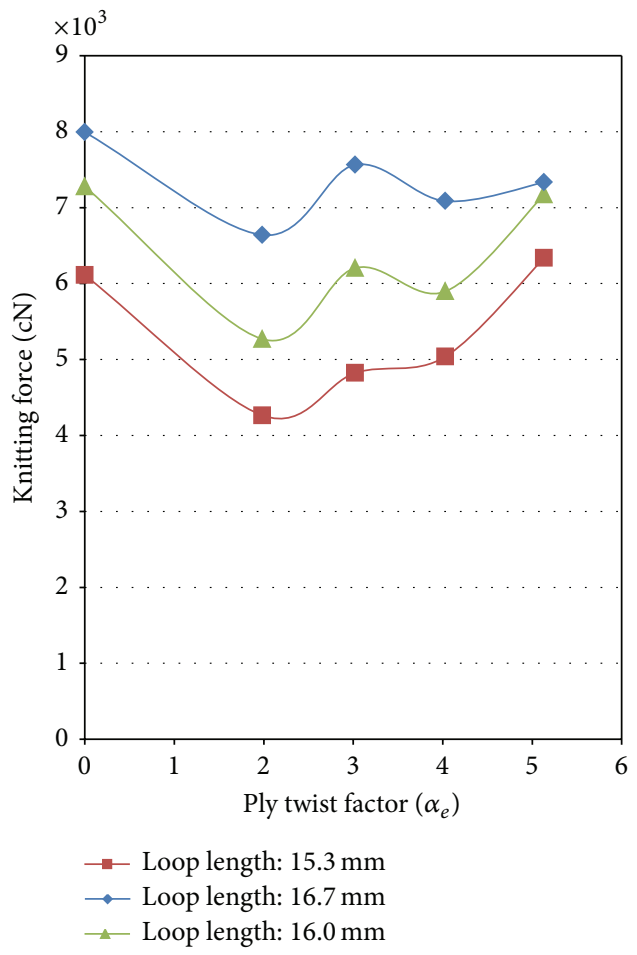

FIGURE 15: Effect of yarn ply twist factor on knitting force in single jersey fabrics.

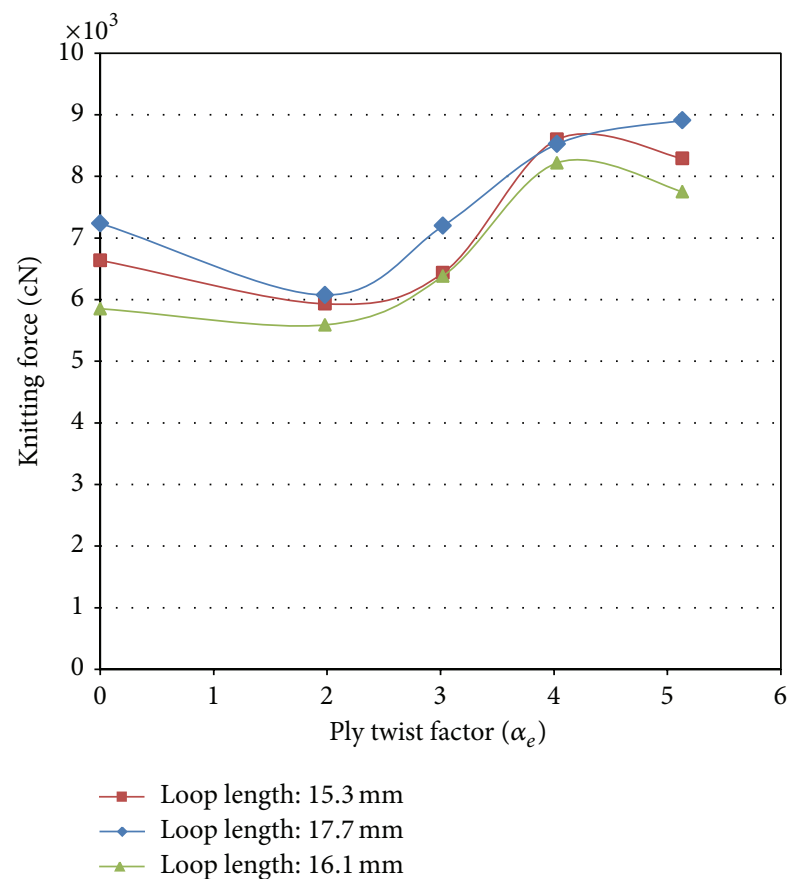

FIGURE 16: Effect of yarn ply twist factor on knitting force in Rib $1 \times$ 1 fabrics.

It should be noted that the knitting force in Rib $1 \times 1$ is higher than single jersey fabric structure \{see Figures 15 and $16\}$.

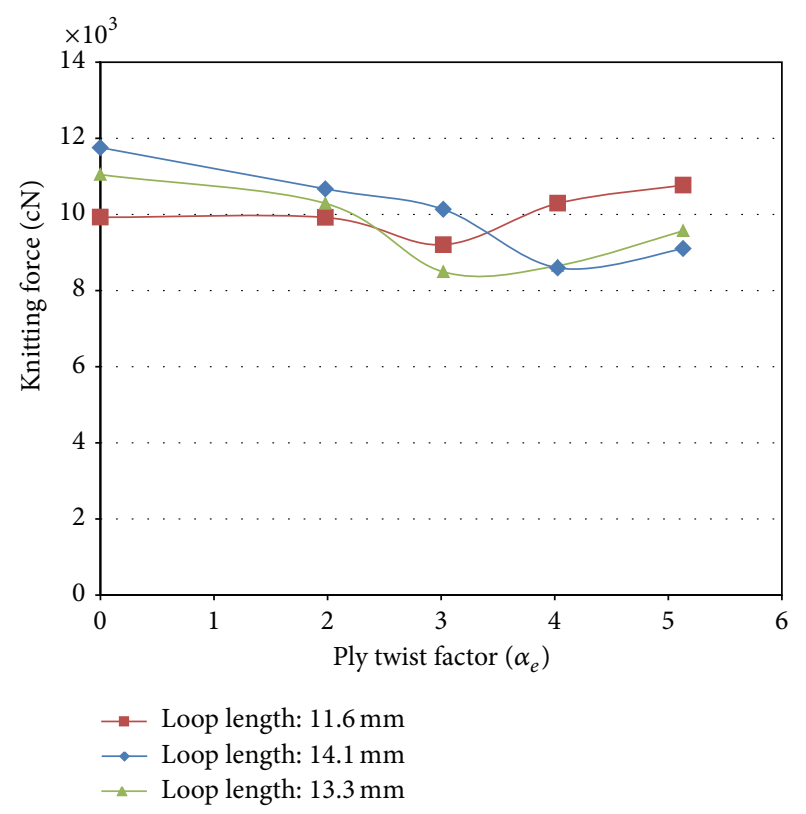

FIGURE 17: Effect of yarn ply twist factor on knitting force in full cardigan fabrics.

It is clear that, from Figure 16, at yarn ply twist factor of $1.98\left(\alpha_{e}\right)$ the knitting forces decreased by $8 \%$ compared with its value at zero yarn ply twist factor. This point can be considered as the optimum setting for Rib $1 \times 1$ fabric structure which gives minimum knitting force regardless of the loop length.

4.3. Full Cardigan Fabrics. The knitting force for full cardigan knitted fabric is higher than the tested previous knitted fabrics (single jersey and Rib $1 \times 1$ ). That is because there is an accumulation of yarns inside the needles hooks, as a result the friction area between the yarn and the needle hook during the casting-off and loop formation is increasing.

Figure 17 demonstrates the effect of yarn ply twist factor on the knitting force in full cardigan knitted fabrics at different levels of loop length.

It is clear from Figure 17 that there is a behavior similarity of the knitting force at different yarn ply twist factors and different loop lengths. It can be seen that the loop length level has no significant effect on the knitting force.

It should be noted that the minimum knitting force can be achieved over the range from 3 to $4\left(\alpha_{e}\right)$ of yarn ply twist factors because the knitting force is decreased by $27 \%$ approximately compared with its value at zero yarn ply twist factor. This range of the ply twist factor can be considered as the optimum setting for full cardigan regardless of the loop length.

It obvious that the optimal setting is achieved at a higher value of ply twist factor because there is an accumulation of yarns and it is likely to increase the friction area as discussed later, but yarn twisting decreases this area and consequently decreases the knitting force. 


\section{Conclusion}

In this research, a novel measuring system for the knitting force in a flat weft knitting machine has been presented and implemented practically. The recorded data from the measuring system has been calibrated to match the knitting force. The analyzed results demonstrated that the proposed system worked effectively and efficiently. In addition, the optimum machine setting has been determined for three well-known fabric structures taking into account the yarn ply twist factor and loop length level.

\section{Conflict of Interests}

The authors declare that there is no conflict of interests regarding the publication of this paper.

\section{References}

[1] J. J. F. Knapton and D. L. Munden, "A study of the mechanism of loop formation on Weft-knitting machinery-part I: the effect of input tension and cam setting on loop formation," Textile Research Journal, vol. 36, no. 12, pp. 1072-1080, 1966.

[2] Wray and Burns, "Analysis of the dry-relaxed knitted loop configuration, part:1 two-dimensional analysis," Journal of the Textile Institute, vol. 58, no. 8, pp. 329-351, 1967.

[3] S. Dönmez and A. Marmarali, "A model for predicting a yarn's knittability," Textile Research Journal, vol. 74, no. 12, pp. 10491054, 2004.

[4] H. Hu and M. Zhu, "A study of the degree of breakage of glass filament yarns during the weft knitting process," Autex Research Journal, vol. 5, no. 3, pp. 141-148, 2005.

[5] X.-M. Liu, N.-L. Chen, and X.-W. Feng, "Effect of yarn parameters on the knittability of glass ply yarn," Fibres and Textiles in Eastern Europe, vol. 16, no. 5, pp. 90-93, 2008.

[6] K. Kowalski, B. Włodarczyk, and T. M. Kowalski, "Probabilistic model of dynamic forces in thread in the knitting zone of weft knitting machines, allowing for the heterogeneity of viscoelasticity yarn properties," Fibres and Textiles in Eastern Europe, vol. 81, no. 4, pp. 61-67, 2010. 

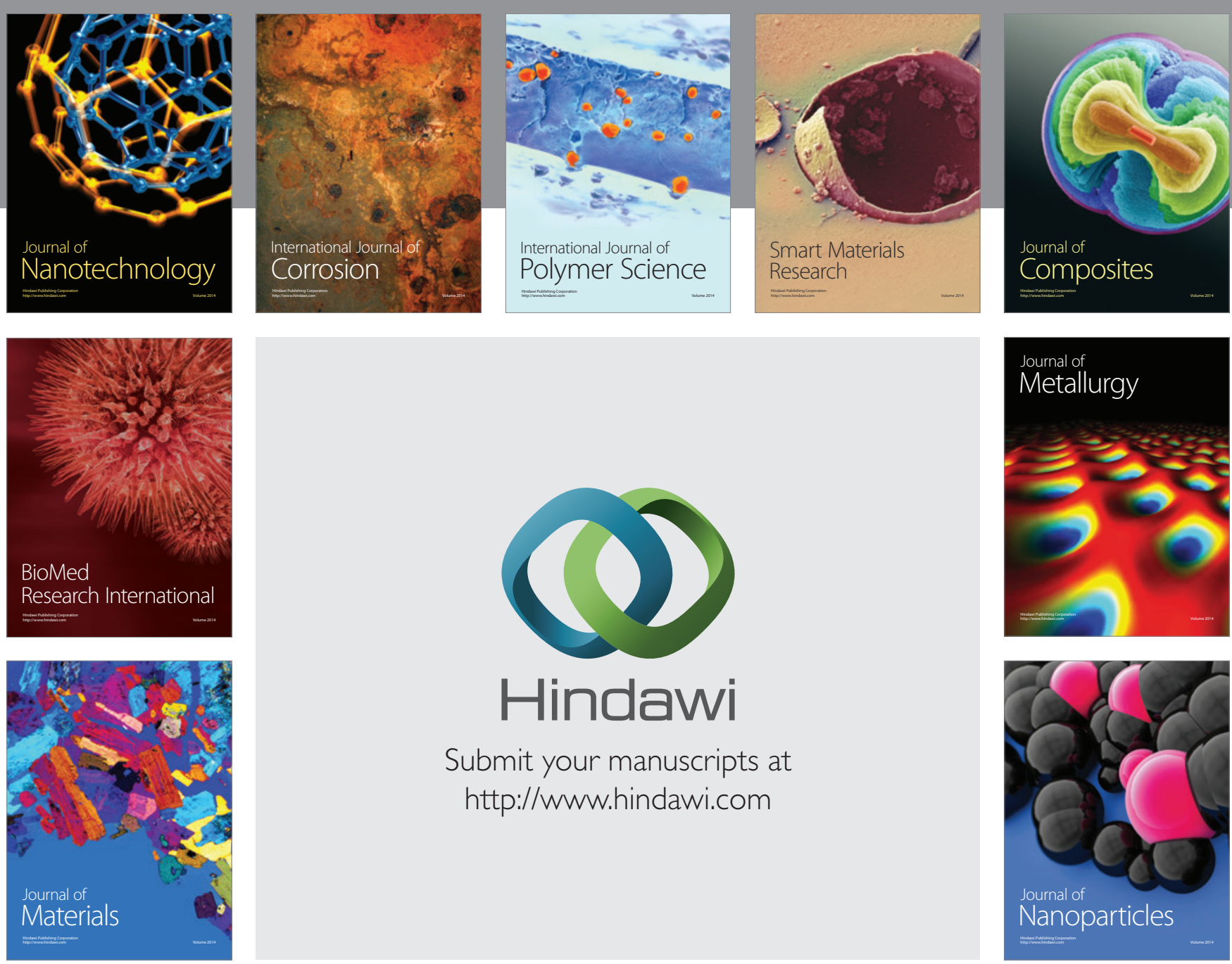

Submit your manuscripts at http://www.hindawi.com
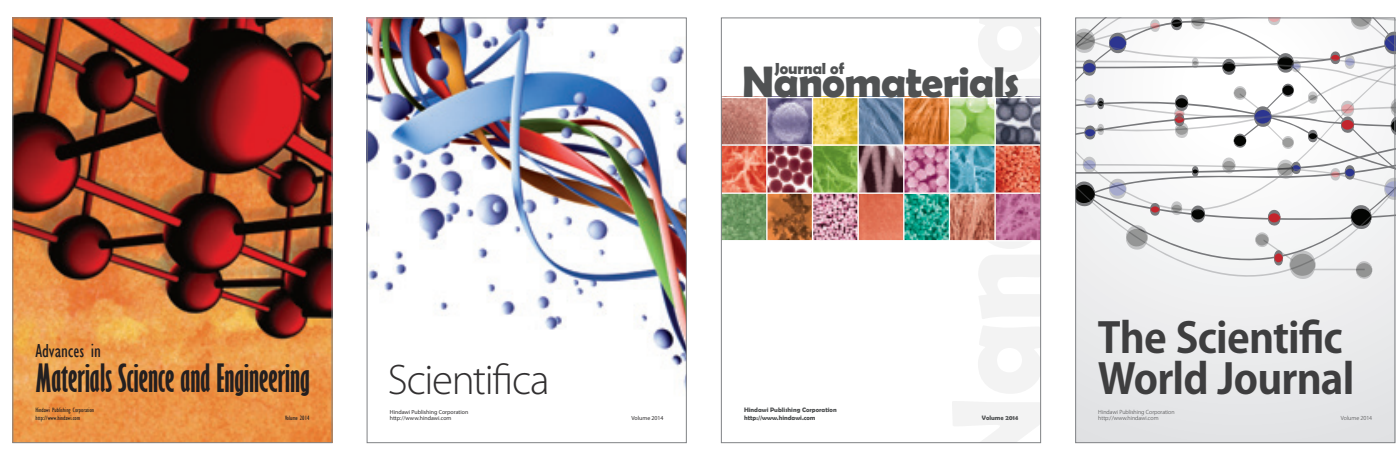

\section{The Scientific World Journal}
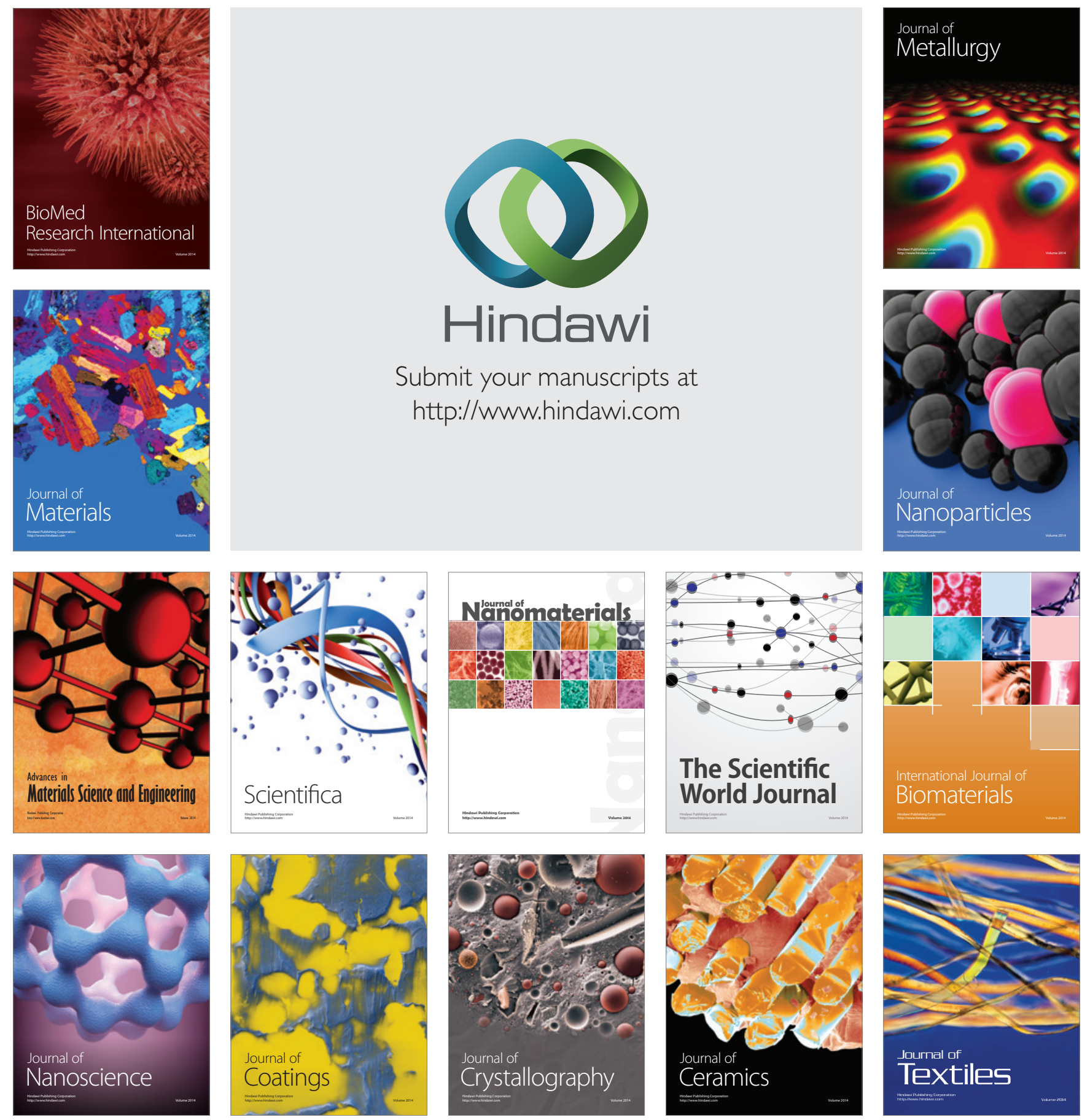